\title{
Profile Interview: Prof. Stephen Gordon
}

"This tree has to be rooted in Malawi, has to be relevant to Malawi, has to address problems that are locally important, has to be grounded well in its departments, has to have branches that can produce good fruits."

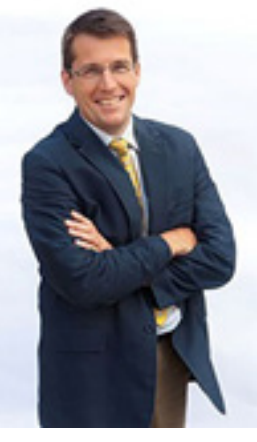

Fanuel Bickton (FB) and Yohane Gadama (YG) interview Prof. Stephen Gordon (SG) on his background, his position as MLW's Director, and the possibility of CHIM studies in Malawi.

FB: Tell us about your personal and professional background.

$S G$ : I was raised in Kenya for nine years of my childhood. I had some primary and secondary education there, and I think that's when I learned to enjoy living in Africa and value the problems of Africa as important. The other half of my upbringing was in Northern Ireland. My father was a CCAP minister at one time but my parents chose to send me to a Catholic school. In Northern Ireland, you will recall, there had been a long-standing conflict between Protestants and Catholics, or two different tribes. So, I learned that working to have people understand each other and work together is very important. Those were the two influences that most shaped how I think. I then went into medicine because I wanted to help people. I studied medicine at Cambridge University starting in 1984, after working for a year in Kuluva Hospital in Uganda as a volunteer. I met my wife at the University and we have worked together ever since.

FB: You are a respiratory medicine specialist. What have you contributed to this field?

SG: I do occasionally get into a little trouble. My original work was discussed in the House of Parliament and there was an attempt to ban it from publication in the UK courts. The reason for that was that my first piece of research was surrounding the respiratory symptoms that were experienced by a group of workers in a glass bottle making factory. The workers were complaining that the conditions in the factory were such that their lungs would be damaged, but the management and the government were saying there was no problem. So, I did an investigation and found that most people had some pieces of the truth but no one had it all. Then the reason that it became political was that the government had claimed they had set up a committee to sort it out but in fact they had done nothing. After my work, overall conditions improved in the factory. The factory is still in business and the conditions are better; so that was good.

My second contribution was here in Malawi, when we started studying lungs in 1997. We noticed that Malawians had a lot of smoke in their lungs even if they didn't smoke tobacco; smoke from how they cook, smoke from traffic, smoke from rubbish bins - we saw a lot of black carbon in the lung cells. We did a lot of work on whether this could affect Malawians' lungs and we were sure that it could. Then, encouraged by Kevin Mortimer, we tried the largest trial of cook stoves that has ever been done, hoping that that would reduce the rate of child pneumonia, which it does not. We showed that improved cook stoves do cause much less smoke, are important for reducing the number of trees we cut down, and reducing the amount of smoke that people breathe. But the simple equation that said if there is less smoke there would be less pneumonia, Date Received: 04 May 2017 was not the case. So, that's a contribution here in Malawi.

Where we are headed now is to try to understand why $40 \%$ of Malawians have reduced lung function. So, we http://dx.doi.org/10.4314/mmj.v29i4.12 are looking at the infectious and non-infectious causes of lung damage throughout the life-span, to try to understand how we can make Malawians' lungs function better.

\section{FB: How did you join MLW and become its leader?}

SG: I came here first in 1996 as one of the first four Wellcome Trust fellows and later as a Career Development Fellow. Since then, MLW has grown from four fellows to 450 staff. Those were the years when Prof Malcolm Molyneux was the Director. Then I went away for a period when my own career grew from being a research fellow to being Head of Department in the Liverpool School of Tropical Medicine, and came back as MLW Director. It feels a bit like this was the last job I had not done; I have done all sorts of other jobs.

\section{YG: What does leading such a huge group involve?}

$S G$ : We are not huge. I would say it's a small-to-medium size research institute. We aspire to grow larger. I think the most enjoyable aspects are the people I work with; interacting with them, enjoying the success of their projects. The most challenging aspect is that there is so much that we could do and we have only a limited amount of time in the week, limited people, limited money - we have limitations on all our resources. Choosing what we can do and what we can't do, because we can't do everything - that's the challenge. How do we deal with that? We have to consult each other, we have to figure out what would be the things we can do that are most useful. I think the number one thing that I have to remind myself of every single day is the importance of humility. There is no one who has all the answers. But if we work as a team, if we ask, we learn from each other. Day to day, a lot of my job is in coaching people to work together in teams, to achieve the best they can.

I am responsible to the College of Medicine; to make sure that we are a good research environment, and that the research we do is excellent and of high quality. I am responsible for excellent training for the next generation of researchers. Now, those are the high-level aims - excellent research and excellent training.

YG: How are you creating a large mass of local researchers and building them to a level where they can be independent and produce high-quality research outputs?

SG: There are 420 Malawians working here and 35 expatriates. We have over 100 post-graduate students of which $72 \%$ 
are from Malawi. I think, in terms of our trajectory, we are taking people through all the training stages. When the first Malawian trainees came in, they were at pre-PhD level but now they are post-doctoral.

Of those first four fellows, Nigel Cunliffe is now Head of Institute in Liverpool, I am Head here, Professor Nynke van den Broek leads in maternal and child health in Liverpool, and Professor Stephen Rodgers is a leading research professor in Melbourne. So, all the early expatriate PhDs became research leaders. Now, our aim is to make sure that the Malawian research students of today become research leaders too. I think it's a matter of being patient.

FB: Talk about the Controlled Human Infection Model (CHIM) studies which you're planning to do in Malawi.

SG: We have begun a conversation about CHIM studies but have no immediate plans. I began doing Human Challenge studies eleven years ago in Liverpool. There are certain settings where it is appropriate to put a pathogen into a human in order to better understand the pathogen and the human, and how they interact. This is particularly important in the development of vaccines and in testing which vaccines work best in a given setting.

Why should we do CHIM studies in Malawi? Most treatments used in Malawi were invented somewhere else for someone else and we just borrow them. Sometimes they work well, sometimes they don't - and that is a problem with vaccines. The best vaccines are locally built for the right population, the right pathogens, and the right exposure. To build and test vaccines in Malawi, we need a way of testing vaccines quickly and in the least number of people. The first two examples we want to look at are pneumococcus and salmonella. One reason to do CHIM studies in Malawi is to make vaccines locally relevant and as effective as possible. But another reason is: if we are a research institute in Malawi, we would like to be world-leading in some aspects - aspects of clinical studies where we can be the best in the world because this is the place where the disease occurs and because we are very good at what we do.

In terms of CHIM studies in Malawi, the general public and the scientific community need to decide whether this is safe and appropriate and there are different ways to do that - by conversation, and by test study with very low risk designs first.

\section{FB: What contributes to the success of MLW?}

SG: I describe this Organization as being like a tree rooted in Malawi. The tree has branches which bear fruits which are products such as vaccines, drugs and diagnostics. Products, people, places and policy - those are fruits - and the research groups bring those fruits out. But there is no plant that does not have roots. The roots are the departments; operation departments, vehicles, safety, nurses, clinicians, statistics - all these departments - and the thing has to work together as a whole.

This tree has to be rooted in Malawi, has to be relevant to Malawi, has to address problems that are locally important, has to be grounded well in its departments, has to have branches that can produce good fruits. We've increased the number of research groups from eight to twelve and we plan to increase, by the end of this year, from twelve to sixteen.

\section{YG: How can aspiring researchers join MLW?}

$S G$ : Now that we have Research Groups, the way that you enter MLW is through those Groups. You ask, "Which one is doing work that I'm interested in?" You attend their lab meetings, or when project progress is presented on Monday afternoons, you go along. Then you develop an idea. That idea goes to the Research Strategy Group. They approve it, then you are in and a part of that Group. That way, you are at home in the MLW by being part of the research. If you want to be more full-time, then you apply for internship to work with a group. The research group is the absolute key unit. Our programs span all the way from Social Science through to Molecular Biology. The whole spectrum is there.

\section{YG: What are your future plans for MLW?}

SG: We would like to see excellent research. There is a concept called "critical mass", where you need enough people to achieve a goal. Certainly, the existing number of research groups is too small. I think if we had 16 active research groups within the next five years, that would be good. In terms of our trainees, if we are going to have independent research professors, I think we probably need to double the number of $\mathrm{PhD}$ students. In terms of our published paper output - we are over 100 papers a year now, it will be nice to increase both the size and the quality but more important, I think, is to increase the number of clinical trials, as they answer questions in a very particular way. In the next period, we want to develop a policy unit so there is more discussion with the Government asking us key questions and us informing the government of relevant findings. 